RAYMOND J. YOUNG: APPLICATION OF THERMOGRAPHY IN PLACENTAL LOCALIZATION

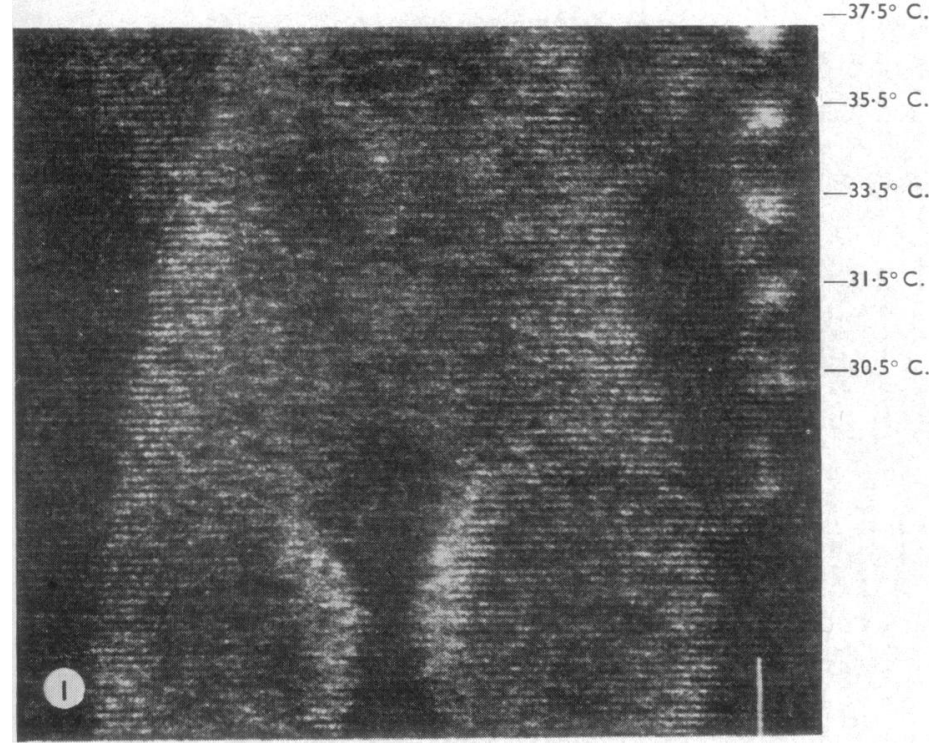

FIG. 1.-A thermograph of a non-pregnant female abdomen with reference added. The lighter areas represent increased radiation, which is particularly noticeable in the inguinal region the medial aspects of the thighs, the flanks, and at the umbilicus.

FIG. 3.-A thermograph of a pregnant abdomen with the placental site shown on the posterior wall of the uterus.

FIG. 4.-A thermograph showing the almost photograph-like quality that may be achieved after some experience in the use of the Pyroscan. The

placental site is clearly seen. Such thermographs as these could be used for studies of placental function.
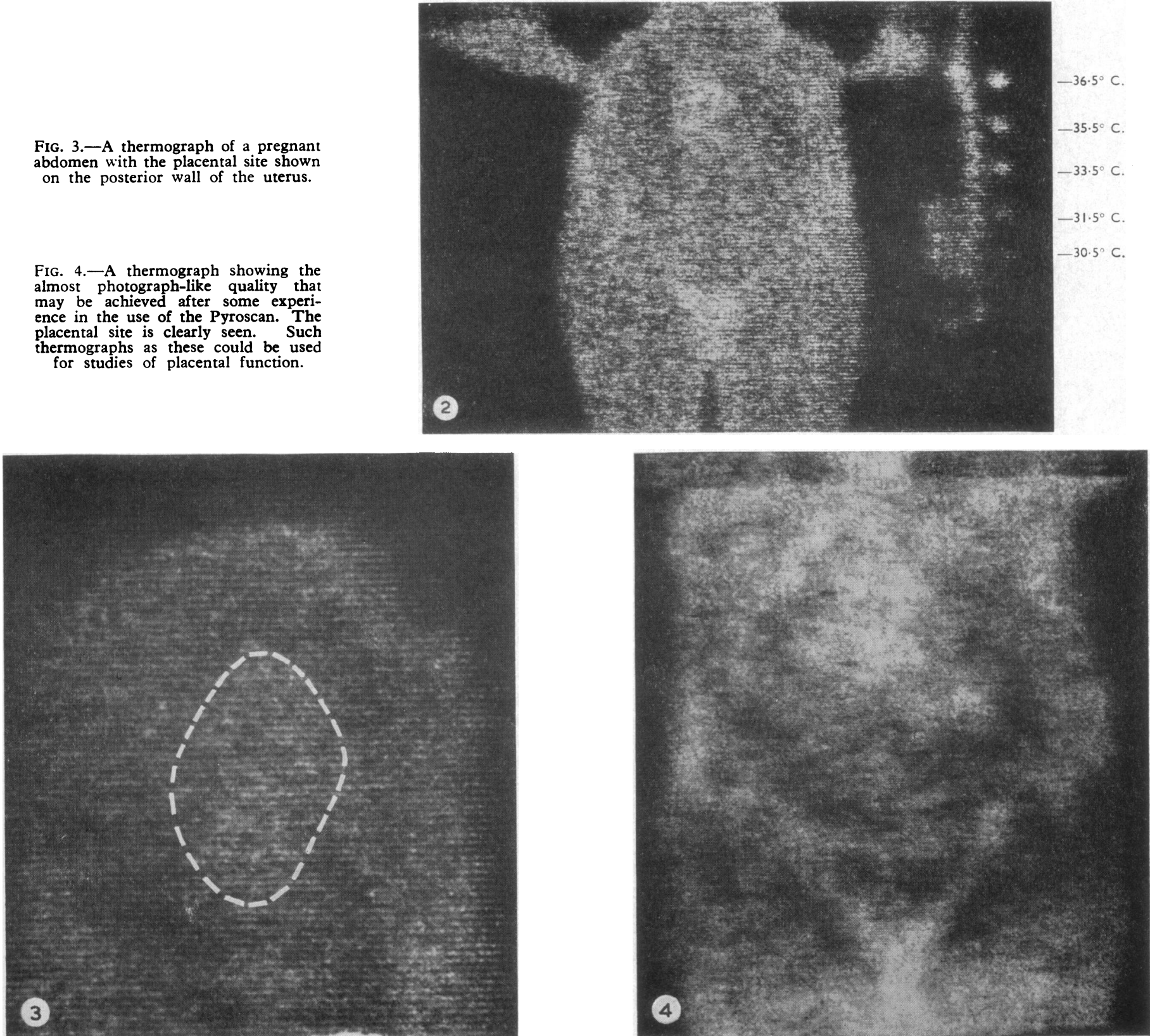
that the gradual reduction of blood-flow associated with the partial occlusion may be responsible for the atrophic changes seen in the proximal convoluted tubules. The fact that the remaining tubules do not develop compensatory hypertrophic change confirms the fact that the blood supply to the cortex is reduced over a period of time.

The distribution of vascular lesions is of some interest when taken in chronological order after transplantation, for those patients who survived the shortest time showed more changes in the smaller vessels, while those who survived for longer periods developed changes in the larger vessels.

The fact that six out of seven kidneys submitted to us had developed vascular changes suggests that this is commoner than was previously thought. It would seem that the variety of suppressive agents used to prevent the rejection syndrome are not themselves responsible for the vascular lesion, although radiation cannot be entirely excluded. It is not clear what factor is responsible for these changes, but as these are discussed by Dempster et al. (1964) they will not be repeated here. Porter et al. (1963) consider that the immunological basis may be responsible, and further thoughts are required on how the vascular lesion can be overcome once the initial stage has been passed.

\section{Summary}

The transplanted kidney of seven patients who survived 9 , $25,26,28,33,126$, and 544 days has been examined by microdissection of the nephron and the renal arterial tree.

In two cases epithelial necrosis was seen in the first part of the proximal convoluted tubule. The desquamated cells had been shed into the lumen and passed down the tubule.

In six cases evidence of hypertrophy of the intima and degeneration of media with aneurysmal dilatation could be demonstrated in the interlobular and arcuate arteries and occasionally in the branches from the interlobar artery.

Microdissection demonstrates the extreme focal and progressive nature of the disease. The evidence here suggests that the shorter the period of time after transplantation the more likely will the more peripheral vessels be affected, and the longer the period of time the more likely are the larger vessels to be affected.

It is suggested that the arterial lesion probably occurs earlier in the syndrome than has previously been described.

This work was supported by Research Grant No. HE-05254 from the National Institute of Public Health Service, U.S.A.

We are indebted to Mr. W. J. Dempster and Professor C. V. Harrison for submitting kidneys for microdissection from Cases 1 , $2,3,4$, and 6 , the case histories of which and the suppressive agents used are detailed in the previous paper (Dempster et al., 1964); to Dr. C. K. Anderson for Case 5, previously reported by Parsons et al. (1963); and to Professor R. Küss and Dr. M. Legrain for Case 7, previously reported by Küss et al. (1963).

\section{REPERENCES}

Anderson, C. K. (1963). Quoted by Parsons et al. (1963)

Calne, R. Y., Loughridge, L. W., MacGillivray, J. B., Zilva, J. F., and Levi, A. J. (1963). Brit. med. Ұ., 2, 645.

Darmady, E. M., Dempster, W. J., and Stranack, F. (1955). F. Path. Bact., 70, 225.

- and Stranack, F. (1957). Brit. med. Bull., 13, 21.

Dempster, W. J. (1953). Brit. F. Surg., 40, 447.

- Harrison, C. V., and Shackman, R. S. (1964). Brit. med. 7., 2, 969.

Goodwin, W. E., Kaufman, J. J., Mims, M. M., Turner, R. D., Ğlassack, R., Goldman, R., and Maxwell, M. M. (1963). F. Urol., 89, 13.

Hamburger, J., Vaysse, J., Crosnier, J., Auvert, J., and Dormont, J. (1963). Bull. Soc. méd. Hôp. Paris, 114, 225.

7. Med., 32, 854. Lalanne, C. M., and Hopper, J. (1962). Amer.

Hume, D. M., Merrill, J. P., Miller, B. F., and Thorn, G. W. (1955). F. clin. Invest., 34, 327.

Küss, R., Legrain, M., Mathé, G., Nedey, R., and Camey, M. (1962). Rev. franc. Etud.' clin. biol., 7, 1048.

Murray, J. E., Merrill, J. (1963). Presse méd., 71, 445.

urray, J. E., Merrill, J. P., Dammin, G. J., Dealy, J. B., Alexandre, G. W., and Harrison, J.' H. (1962). Ann. Surg., 156, 337. Harrison, J. H., Wilson, R. E., and Dammin, G. J. (1963). New Engl. 7. Med., 268, 1315 .

Parsons, F. M., Markland, C., Raper, F. P., and Fox, M. (1963). Brit. med. 7., 1, 930.

Porter, K. A., Thomson, W. B., Owen, K., Kenyon, J. R., Mowbray, J. F., and Peart, W. S. (1963). Ibid., 2, 639.

\title{
Application of Thermography to the Problem of Placental Localization: Preliminary Communication
}

\author{
RAYMOND J. YOUNG,* M.B., B.S.
}

[With Special Plate]

Brit. med. F., 1964, 2, 978-981

Most obstetricians would agree that a method for accurate localization of the placenta in a pregnant uterus would constitute a significant contribution to antenatal care and management of labour. For instance, many women who have a small ante-partum haemorrhage are confined to hospital for many weeks and may eventually come to examination under anaesthesia with all its attendant risks to mother and foetus. This is sound and common practice, yet it is a reflection of the faith which obstetricians have in techniques of placental localization available at the moment. There is little to choose between the present techniques of placental localization, since all of them involve the use of ionizing radiations.

Radiological techniques may involve the skilled interpretation of soft-tissue $x$-ray films. This method may be augmented by the use of contrast media in the bladder and rectum. Good results have been reported in relation to placenta praevia. Donald (1964a) reports a 97\% accuracy from his unit. More elaborate radiological techniques involving the use of intravascular contrast media are usually applied to special cases and are not in routine clinical use.

Radioactive isotopes have successfully demonstrated the placental site and have given a clue to problems of placental function (Browne and Veall, 1953 ; Hibbard, 1962). However, a low, acceptable dose of radio-isotope has the disadvantage of making localization of placentae on the posterior uterine wall very difficult and uncertain. The techniques involving

* Registrar to Department of Obstetrics, Bedford General Hospital. 
both $x$-ray contrast media and isotopes depend upon the rich vascular supply of the placenta, and it seems likely that thermographic techniques also depend upon this. Thermographic techniques have the advantage of being quick, simple, and completely harmless to mother and foetus. The Pyroscan has a truly passive detection system.

Thermography has an established value in the diagnosis and prognosis of breast carcinoma (Lawson, 1956 ; Lloyd Williams, Lloyd Williams, and Handley, 1960, 1961). Vascular disturbances such as a block in a blood-vessel are demonstrated beautifully by thermography (Barnes, 1963). A technique of non-contact temperature measurement is probably of significance as an index of activity in a joint affected by rheumatoid arthritis. Experiments in thermography relating to burns have shown promise in differentiating between areas of vascular damage in the skin and less vitally damaged areas.

It was the above work that raised the hope that sufficient heat might arise in a placenta to alter significantly the thermal contours of the skin and that these changes might be related to the placental site.

\section{Selection of Cases}

It is an easy matter to show changes in thermal contour when comparing a pregnant and a non-pregnant female abdomen, but quite another thing to interpret these changes in terms of placental situation and, furthermore, to prove conclusively the accuracy of these predictions. For the purposes of this study it would be indefensible to complicate normal labour by any effort to prove the accuracy of a prediction of placental site. In one case of forceps extraction under general anaesthesia a specially gloved hand was introduced immediately into the uterus after birth of the foetus, but even in this case the placenta was partially separated and only a vague impression of its site obtained (Case 14). For the purposes of this investigation the predicted placental site could be confirmed only at caesarean section, when it is possible to introduce a hand into the uterus before the placenta separates. Cases were therefore selected for thermographic study upon their liability to be delivered per abdomen. Forty-seven cases were studied, and 13 of them came to section and predictions were assessed. In this communication only the cases that came to be sectioned are discussed.

\section{Apparatus Used}

A Pyroscan was used to produce the thermographs in this series. Precise details of the mode of operation of this infrared detection apparatus are outside the scope of this communication. Very briefly, however, a surface-silvered plane scanning mirror reflects infra-red emissions from the subject's skin on to a spheroidal mirror and thence to a detector cell set at the centre of focus of this mirror. A feeble signal, proportional to incidental heat-radiation, is produced by the indium antimonide photoconductive cell, which operates at the temperature of liquid nitrogen. A voltage gain of about one million is achieved by a multistage amplifier. In this way a black-and-white picture can be written upon electrosensitive paper, where the grey scale is proportional to temperature.

\section{Experimental Conditions}

Ideally, thermographs should be made in a room where the environment is constant in that humidity and temperature are strictly controlled and where there is complete absence. of draughts and other sources of heat-emission other than that of the subject. The ideal room temperature is said to lie between $15^{\circ}$ and $20^{\circ}$ C. (Lloyd Williams and Cade, 1964). The human subject both emits and reflects infra-red radiation.
The rate of flow of these radiations is by no means constant. This flow of heat is in a dynamic equilibrium with the environment and a normal physiological process by which the organism maintains the constancy of its internal environment. Thus actual measurements of skin temperature mean nothing and the symmetry of this flow pattern is the significant value of a thermograph. This important point is well brought out by Lloyd Williams and Cade (1964). About two hours are required for a human subject to reach thermal equilibrium with its surroundings, and it would be ideal to leave the body unclothed in the environment of the Pyroscan for this time.

In this study the ideals of machine environment and the subject's thermal equilibrium were observed so long as they were simple, quick, and convenient. However, the true worth of thermography in clinical practice can be really assessed only if the apparatus is made to give consistent results in non-ideal conditions.

Accordingly a small room with a northern aspect and a large window was chosen for the environment of the apparatus. All heating was turned off. The temperature was between $20^{\circ}$ and $23^{\circ} \mathrm{C}$. The subject was prepared by surface chilling with a towel made damp by cold tap-water. The duration of this chilling was about 10 minutes and sufficient to cause superficial vasoconstriction. This vasoconstriction is advantageous (Lloyd Williams et al., 1960, 1961) and enhances thermal contrast. The rapid scanning speed of the Pyroscan was relied upon to minimize averaging effects of rate of cooling and to approximate to an instantaneous thermograph. The rapid scanning technique also was advantageous to allow the thermograph to be completed between quite frequent labour contractions. No patient in this study except the non-pregnant controls complained of discomfort during surface chilling.

After examination with the Pyroscan a note was taken by line diagrams. At section the foetus was delivered and handed over to the assistant at once, the hand being introduced into the uterus at the same moment. Speed is essential, since the uterus retracts rapidly around the placenta. The first impression is therefore the most accurate. Even this simple manœuvre might produce spurious results. Donald (1964b) comments that the localization of the point of adhesion of morbidly adherent placentae seems to vary according to whether the operator is left-handed or right-handed. It is hoped that to be aware of this subjective source of error is sufficient to avoid it. Three of the sections were performed by experienced obstetricians who had no foreknowledge of the predicted placental site.

\section{Interpretation of Thermographs}

Interpretation is considerably simplified, particularly with poor thermographs, by closed-circuit television using a telephoto lens on the camera. A much magnified image is produced and the image contrast may be emphasized by using the controls on the monitor. This arrangement was found to be of great value early in the series, when facility in the use of the Pyroscan's own gain and contrast controls was yet to be achieved.

Thermographs, like radiographs, are often difficult to interpret until some experience is gained. In this study only anterior views were used. Lateral thermographs are disappointing at the moment.

As a preliminary step the normal thermal contours of a non-pregnant abdomen should be considered. Fig. 1 (Special Plate) is a thermograph showing an increase in radiation (lighter in the picture) in the inguinal region, the medial aspects of the thighs, the flanks, and at the umbilicus. This increased radiation is a manifestation of cross-radiation and is normal. (The subject was a slim woman with a deep umbilicus.) A black body reference radiator included on the right of the picture shows the umbilicus to be about $1^{\circ} \mathrm{C}$. "hotter" than the rest 
Analysis of Results

\begin{tabular}{|c|c|c|c|c|c|c|c|}
\hline $\begin{array}{l}\text { Case } \\
\text { No. }\end{array}$ & Subject & $\begin{array}{l}\text { Duration } \\
\text { of Cyesis } \\
\text { in Weeks }\end{array}$ & $\begin{array}{l}\text { Pyroscan's } \\
\text { Ambient } \\
\text { Temp. }{ }^{\circ} \mathbf{C} \text {. }\end{array}$ & $\begin{array}{c}\text { Placental Site } \\
\text { at } \\
\text { L.S.C.S.* }\end{array}$ & $\begin{array}{l}\text { Accuracy } \\
\text { of } \\
\text { Prediction }\end{array}$ & Surgeon & $\begin{array}{l}\text { Quality } \\
\text { of } \\
\text { Thermograph } \dagger\end{array}$ \\
\hline $\begin{array}{r}1 \\
2 \\
16\end{array}$ & $\begin{array}{l}\text { Elderly primip. Thin. Elective } \mathrm{C} / \mathrm{S} \\
\text { Obese diabetic. Hydramnios } \\
\text { Failed trial labour. Average subject }\end{array}$ & $\begin{array}{l}\text { Term } \\
37 \\
42\end{array}$ & $\begin{array}{l}21 \\
22 \\
23\end{array}$ & $\begin{array}{l}\text { F. Part D. Post. wall } \\
\text { E. Post. wall } \\
\text { A. Part B. Going on to Rt. }\end{array}$ & $\begin{array}{c}\text { Exact } \\
\# \\
\#\end{array}$ & $\begin{array}{l}\text { R.J.Y. } \\
\text { J.R.H. } \\
\text { R.J.Y. }\end{array}$ & $\begin{array}{l}2 \\
2 \\
2 . \quad \text { Cell coolant }\end{array}$ \\
\hline $\begin{array}{l}17 \\
20 \\
21 \\
26\end{array}$ & $\begin{array}{l}\text { Elderly primip. Thin } \\
\text { Disproportion. Ruptured membranes } \\
\text { Previous C/S. Average subject" }\end{array}$ & $\begin{array}{l}39 \\
41 \\
39 \\
\text { Term }\end{array}$ & $\begin{array}{l}23 \\
22 \\
21 \\
20\end{array}$ & $\begin{array}{l}\text { F. Part D. Ant. wall } \\
\text { Central post. wall } \\
\text { Central C. D. Post. wall } \\
\text { D. Going on to lat. wall. }\end{array}$ & "’ & $\begin{array}{l}\text { R.J.Y. } \\
\text { R.J.Y. } \\
\text { R.J.Y. } \\
\text { R.J.Y. }\end{array}$ & $\begin{array}{l}\text { 2. High humidity } \\
4 \\
5 \\
4\end{array}$ \\
\hline 31 & Elderly primip. Breech. Thin & 39 & 21 & Lt. cornua, going on to ant. & " & R.J.Y. & 4 \\
\hline 34 & $\begin{array}{l}\text { Disproportion. Ruptured membranes. } \\
\text { Frequent contractions }\end{array}$ & 41 & 21 & B. Part D. Post. wall & $\begin{array}{l}\text { Pyroscan: } \\
\text { central } \\
\text { A B C D }\end{array}$ & R.J.Y. & $\begin{array}{l}\text { 3. Hurried } \\
\text { recording }\end{array}$ \\
\hline $\begin{array}{l}35 \\
37 \\
45\end{array}$ & $\begin{array}{l}\text { Failed trial labour. Obese } \\
\text { Failed trial labour } \\
\text { Disproportion. Thin }\end{array}$ & $\begin{array}{l}41 \\
41 \\
\text { Term }\end{array}$ & $\begin{array}{l}22 \\
22 \\
22\end{array}$ & $\begin{array}{l}\text { B. Part D. Post. wall } \\
\text { D. Post. wall } \\
\text { B. Going on to lat. wall. }\end{array}$ & $\begin{array}{l}\text { Exact } \\
\text { ” }\end{array}$ & $\begin{array}{l}\text { R.J.Y. } \\
\text { R.J.Y. } \\
\text { J.R.S. }\end{array}$ & $\begin{array}{l}4 \\
4 \\
4\end{array}$ \\
\hline 46 & Previous C/S. Unstable lie & 39 & 22 & $\begin{array}{l}\text { Anterior } \\
\text { A and B. Post. wall }\end{array}$ & ", & J.R.S. & 4 \\
\hline
\end{tabular}

* The placental sites are shown in the Diagram.

the operation of the Pyroscan. Other causes are noted.

of the abdomen. ${ }^{1}$ This normal temperature rise at the umbilicus is believed to be highly significant in the interpretation of thermal contours of the pregnant abdomen. Pubic hair intercepts infra-red radiation from the mons pubis.

For comparison, the pregnant abdomen at term is shown with reference added (Special Plate, Fig. 2). The increased radiation in the inguinal region, flanks, and thighs is less obvious, but the exposed labia are prominent. It is immediately obvious that the area of radiation from the umbilicus is much larger and the site of a $2^{\circ}-3^{\circ} \mathrm{C}$. rise in temperature. Experience has shown that the umbilicus acts as a radiator of placental heat if the placenta is anywhere in the vicinity of the umbilicus. It appears to be immaterial to the Pyroscan whether the placenta is on the anterior or the posterior wall of the uterus. Often a heat " flare" can be seen leading from the umbilicus, as is shown in Fig. 1 and to the left in this case; this flare provides a more accurate means of localizing placenta in this situation.

In accordance with the basic cosine law of Lambert less radiation is expected in parts of a thermograph away from the maximum convexity of the pregnant uterus. Increased radiation from these peripheral areas is therefore highly significant. There is an impression that increased definition tends to improve up to term and, as would be expected, to deteriorate in gross cases of post-maturity. Disappointing thermographs are produced in cases of pre-eclamptic toxaemia before 37 to 38 weeks of the pregnancy. It is also disappointing and paradoxical that the placental site seems to be no more obvious in cases of twin pregnancy.

Too close comparison between the pregnant and the nonpregnant abdomen is apt to be speculative, since the physical properties in terms of emissivity of the stretched skin of the pregnant abdomen are not known at present. Pigmentation must also be taken into account.

The Pyroscan occasionally writes a circle in close proximity to an area of increased radiation. This "circle effect" can also be seen on thermographs from other sources-for example, a case of breast carcinoma reproduced by Lloyd Williams and Cade (1964). This fact can be misleading in cases where thermal contours are indefinite. The source of this effect is thought not to be electronic in origin, since subjects have to be checked with a thermopile and corresponding temperature evaluations found. The precise mechanism requires further investigation.

\section{Results}

Fig. 3 (Special Plate) depicts a thermograph of Case 21 showing clearly the placental site as a central "hot" area. The membranes were ruptured in this case and the subject was in labour. At caesarean section the placenta lay on the posterior wall of the uterus exactly as predicted.
The Table above gives an analysis of results that is self-explanatory. The position of the placenta found at operation is noted by reference to the following diagram. No cases in this series were found to have the placenta in either the fundus or the lower segment of the uterus.

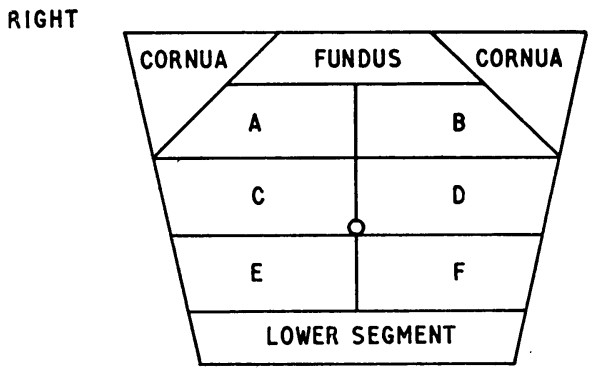

LEFT

(1)

Line diagram representing the uterus as seen in a coronal plane at caesarean section. Letter reference is added. This is an approximation to simplify records.

Statistical analysis is not required to show that the results are unlikely to be achieved by chance and are therefore significant.

In all cases except one (No. 34) the prediction of placental site proved to be completely accurate except it could not be forecast whether the placenta was on the anterior or the posterior wall of the uterus. This one error, though slight, is most interesting (Case 34). Thermographs indicated the centre of the placenta to be about $3 \mathrm{in}$. $(7.5 \mathrm{~cm}$.) medial to the true centre found at operation. However, examination of the lateral one-third of the placenta showed it to be almost completely infarcted and presumably non-functional.

\section{Conclusions}

In all the cases of this series the placental site was predicted in one plane with sufficient accuracy for practical purposes. The problem of localization in depth is being investigated with the Diasonoscope. More experience is required before comment can be made. Thermography also holds promise in the investigation of placental function. For instance, Fig. 4 (Special Plate) shows the almost three-dimensional effect that can be produced in a thermograph with experience. In fact, the operator of the Pyroscan in this case was its designer. The placental site is very clear.

It should be emphasized that the precise cause of the changes in heat contours corresponding to the site of the placenta is

1 The black body reference radiator referred to here shows itself on a thermograph as a series of spots in varying shades of grey that represent heat emissions of known temperature. This calibrating scale is to be seen to the right of Figs. 1 and 2 . It is of interest that such a reference radiator is surprisingly difficult to design and develop. 
not known. It is conceivable that the heat from the placenta on the anterior wall of a uterus might soak through a thin abdominal wall, but it is difficult to understand how thermal contours were altered by a placenta situated upon the posterior uterine wall of an obese patient with hydramnios as in Case 2. The radiator effect of the umbilicus has been mentioned, but this question remains open and is the subject of further investigation. It is just possible that the vasomotor nervous system is involved to a large extent.

\section{Summary}

The problems of placental localization and other applications of thermography are reviewed briefly to indicate the rationale of a trial of the Pyroscan and its theoretical advantages.

Cases were selected for thermographic study upon their liability to be delivered per abdomen. From 47 cases studied 13 came to section and the accuracy of predictions is assessed and discussed.

A basic description of the Pyroscan is given, and experimental methods and conditions are described.
Interpretation of thermographs of the pregnant abdomen is discussed with reference to the thermal contours of nonpregnant controls.

The results showed that the site of functional placental tissue could be accurately predicted in one plane in all the cases that came to section.

I am indebted to Mr. J. R. Hassard and Mr. J. R. Saunders, consultant obstetricians, for their enthusiastic help and the reference of their patients; to Mr. C. Maxwell Cade, chief research engineer (infra-red) for S. Smith and Son Ltd., for his technical advice; and to the directors of S. Smith and Son Ltd. for loan of the apparatus.

\section{REFERENCES}

Barnes, R. B. (1963). Science, 140, 870.

Browne, J. C. M., and Veall, N. (1953). F. Obstet. Gynaec. Brit. Emp., 60, 141 .

Donald, I. (1964a). Practical Obstetric Problems, p. 317. Lloyd-Luke,

London.

Hibbard, B. M. (1962). Proc. roy. Soc. Med., 55, 640.

Hibbard, B. M. (1962). Proc. roy. Soc. Med., 55, 640.

Lloyd Williams, K., and Cade, C. M. (1964). Med. biol. Ill., 2, 105.
Lloyd Williams, F., and Handley, R. S. (1960). Lancet, 2, 958. - Lloyd Williams, F., and Handley,

\title{
Protection of Mice by Interferon Against Systemic Virus Infections
}

\author{
N. B. FINTER,* M.B., B.CHIR., M.R.C.P.
}

Brit. med. F., 1964, 2, 981-985

Many workers have described inhibition by interferon of the growth of viruses in tissue culture cells. In comparison there are only a few references to effects of interferon in animals. These for the most part have described prophylactic effects against a local infection with a virus subsequently inoculated into the same anatomical site. Experiments are here described in which potent preparations of mouse interferon injected subcutaneously or intramuscularly protected mice against intraperitoneal infections with encephalitis viruses.

\section{Materials and Methods}

Viruses. - The MB strain of Semliki Forest virus has been described elsewhere (Finter, 1964a). Encephalomyocarditis (EMC) virus was obtained from Dr. E. M. Martin, National Institute for Medical Research, and passaged in L cell-tissue cultures. West Nile virus was obtained from Dr. J. S. Porterfield, National Institute for Medical Research, and passaged in the brains of mice.

Interferon.-This was prepared from the brains of mice infected with West Nile virus. A $10 \%(w / v)$ suspension of infected brains was made in Hanks's saline, and twice centrifuged at $79,000 \mathrm{~g}$ to sediment virus particles. The final

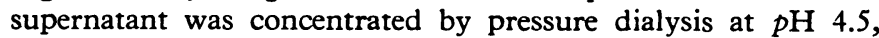
at which level some inactive protein precipitated (A. Davies, personal communication). The $\mathrm{pH}$ was adjusted to 7 , and the material was clarified by low-speed centrifugation. The final products, in which no infective virus could be detected, contained about 40,000 units of interferon per ml., as measured

* Research Department, Imperial Chemical Industries Limited, Pharmaceuticals Division, Alderley Park, Macclesfield, Cheshire. in vitro by the quantitative haemadsorption assay technique (Finter, 1964b). Control preparations of uninfected normal mouse brains were made by the same method. Fuller details of these preparations will be given elsewhere.

Protection Experiments.-Various doses of interferon and times of administration were tested. Groups of 10 male mice $(15-20$ g.) were used for each treatment, the weights of all mice in an experiment being within a 2-g. range. Mice were dosed with interferon by the intramuscular route $(0.1 \mathrm{ml}$.) or by the subcutaneous route $(0.2 \mathrm{ml}$.). Viruses were inoculated by the intraperitoneal route $(0.2 \mathrm{ml}$. per mouse). In each experiment the challenge virus was titrated in parallel, and the actual dose used for challenge was calculated. Cages were inspected at 9 a.m. and 5 p.m. each day. For purposes of calculation, mice found dead-for example, at 9 a.m. on the fifth day after virus infection-were assumed to have died at 5 days. Additional mice dying up to 5 p.m. on the same day were assumed to have died at $5 \frac{1}{2}$ days. Protection conferred by interferon was shown by an increase in the number of mice surviving infection or by a prolongation in the survival time as compared with control mice. The mean of the reciprocals of the days of death (M.R.D.D.) for all mice in a group was calculated. The longer the average period of survival in a group of mice the smaller the value for the M.R.D.D. Differences between the M.R.D.D. values for different groups were tested for significance.

Statistics.-It was found that the reciprocal of the day of death was normally distributed, and therefore this transformation was adopted for analysis. Because mice in some groups survived the virus infection the distribution was truncated, and the technique of Gupta (1952) was used to estimate the means and their corresponding standard deviations. The mean value 